\title{
Clinical relevance of "bulging eyes" for the differential diagnosis of spinocerebellar ataxias
}

Relevância clínica do "bulging eyes” para o diagnóstico diferencial das ataxias espinocerebelares Adriana Moro', Renato Puppi Munhoz', Walter Oleschko Arruda', Salmo Raskin², Hélio Afonso Ghizoni Teive

\begin{abstract}
Objective: To investigate the relevance of the clinical finding of bulging eyes (BE) in a large Brazilian cohort of spinocerebellar ataxias (SCA), to assess its importance in clinical differential diagnosis among SCA. Methods: Three hundred sixty-nine patients from 168 Brazilian families with SCA were assessed with neurological examination and molecular genetic testing. BE was characterized by the presence of eyelid retraction. Genetically ascertained SCA3 was detected in 167 patients, SCA10 in 68 patients, SCA2 in 20, SCA1 in 9, SCA7 in 6 , and SCA6 in 3 patients. Results: BE was detected in 123 patients with SCA (33.3\%), namely 109 of the 167 SCA3 patients (65.3\%) and in 5 of the others SCA patients (1 SCA10 patient, 2 SCA1 patients and 2 SCA2 patients). Conclusion: BE was detected in the majority of patients with SCA3 (65.3\%) and could be used with a clinical tool for the differential diagnosis of SCA.
\end{abstract}

Key words: spinocerebellar ataxias, exophthalmos, Machado-Joseph disease.

RESUMO

Objetivo: Investigar a relevância do achado clínico de bulging eyes (BE) em uma grande amostra brasileira de pacientes com ataxias espinocerebelares (AEC), para avaliar sua importância no diagnóstico diferencial entre as AEC. Métodos: Foram avaliados 369 pacientes de 168 famílias brasileiras com AEC através de exame neurológico e testes de genética molecular. BE foi caracterizado pela presença de retração palpebral. AEC3 foi determinada geneticamente em 167 pacientes, AEC10 em 68 pacientes, AEC2 em 20, AEC1 em 9, AEC7 em 6 e AEC6 foi encontrada em 3 pacientes. Resultados: BE foi detectado em 123 pacientes com AEC (33,3\%), correspondendo a 109 dos 167 pacientes com AEC3 (65,3\%) e 5 pacientes com outras AEC (1 paciente com AEC10, 2 AEC1 e 2 pacientes com AEC2). Conclusão: BE foi detectado na maioria dos pacientes com AEC3 (65,3\%) e poderia ser usado com uma ferramenta clínica para o diagnóstico diferencial das AEC.

Palavras-Chave: ataxias espinocerebelares, exoftalmia, doença de Machado-Joseph.

Spinocerebellar ataxias (SCA) are autosomal dominant inherited ataxias, which constitute a heterogeneous group of typically late-onset, progressive, and often fatal neurodegenerative disorders. Globally, SCA are considered rare disorders, with prevalence estimates varying from 1 to 5 cases per 100,000 individuals ${ }^{1}$. Machado-Joseph disease, also known as spinocerebellar ataxia type 3 (SCA3), is currently considered the most common form of SCA worldwide. Among SCA, the relative frequency of SCA3 in Brazil is about $69-92 \% \%^{2,3}$.

SCA3 is a multisystem neurodegenerative disorder involving predominantly the cerebellar, pyramidal, extrapyramidal, motor neuron and oculomotor systems. Minor, but more specific features such as external progressive ophthalmoplegia
(EPO), dystonia, intention fasciculation-like movements of facial and lingual muscles, as well as bulging eyes (BE), may also be of major importance for the clinical differential diagnosis of SCA $3^{4}$.

The main purpose of this study was to investigate the relevance of the finding of BE in a large Brazilian cohort of SCA and to assess its importance in clinical differential diagnosis among various forms of SCA.

\section{METHODS}

There were studied 369 patients from 168 families with SCA extracted from a large Brazilian cohort. Inclusion criteria

\footnotetext{
Study carried out at Hospital de Clínicas, Universidade Federal do Paraná (UFPR), Curitiba PR, Brazil.

'Movement Disorders Unit, Neurology Service, Hospital de Clínicas, UFPR, Curitiba PR, Brazil;

${ }^{2}$ Genetika Laboratory, Curitiba PR, Brazil.

Correspondence: Hélio Afonso Ghizoni Teive; Rua General Carneiro 1.103 / 102; 80060-150 Curitiba PR - Brasil; E-mail: hagteive@mps.com.br

Conflict of interest: There is no conflict of interest to declare.

Received 08 January 2012; Received in final form 26 February 2013; Accepted 05 March 2013.
} 
were a progressive clinical phenotype in which ataxia was the prominent symptom and a positive familial history compatible with autosomal dominant inheritance. Patients with ataxia secondary to alcohol abuse, inflammatory, neoplastic, paraneoplastic, vascular, or well-defined metabolic diseases were excluded from this study. All patients were assessed with neurological examination and molecular genetic testing for SCA types 1, 2, 3, 6, 7, 8, 10, 12, 14, 17 and dentatorubralpallidoluysian atrophy (DRPLA).

$\mathrm{BE}$ was characterized by the presence of eyelid retraction or eyelid lag according to predefined literature definitions ${ }^{5,6}$ and included in clinical criteria of Machado-Joseph disease by Coutinho et $\mathrm{al}^{4}$ (Figure).

Signed informed consents were obtained following a protocol approved by the Institutional Ethics Committee of the Universidade Federal do Paraná.

\section{RESULTS}

A mutation was identified in $74.3 \%$ of the patients, with SCA3 being the most frequent (45.3\%). SCA10 represented the second most common (18.4\%), followed by SCA2 (5.4\%), SCA1 $(2.4 \%)$, SCA7 (1.6\%), and SCA6 (0.8\%). The remaining $25.7 \%$ of patients were left undiagnosed genetically.

Among the affected patients examined, 53.7\% were male. Age at onset ranged from 6 to 75 years with a mean of $34.5 \pm 10.0$ years, and time from disease onset was $9.3 \pm 7.4$ years (variance 1-37 years).

Table 1 shows a brief summary of clinical data of the SCA type $1,2,3,6,7,10$ and the overall group of SCA. In comparison with other SCA, those patients with SCA3 presented more frequently with eyelid retraction. BE was detected in 123 patients with SCA (33.3\%), namely 109 (65.2\%) of the 167 SCA3 patients and in $5(4.7 \%)$ of the others SCA patients (1 SCA10 patient, 2 SCA1 patients and 2 SCA2 patients) (Table 2). BE was significantly more frequent among patients

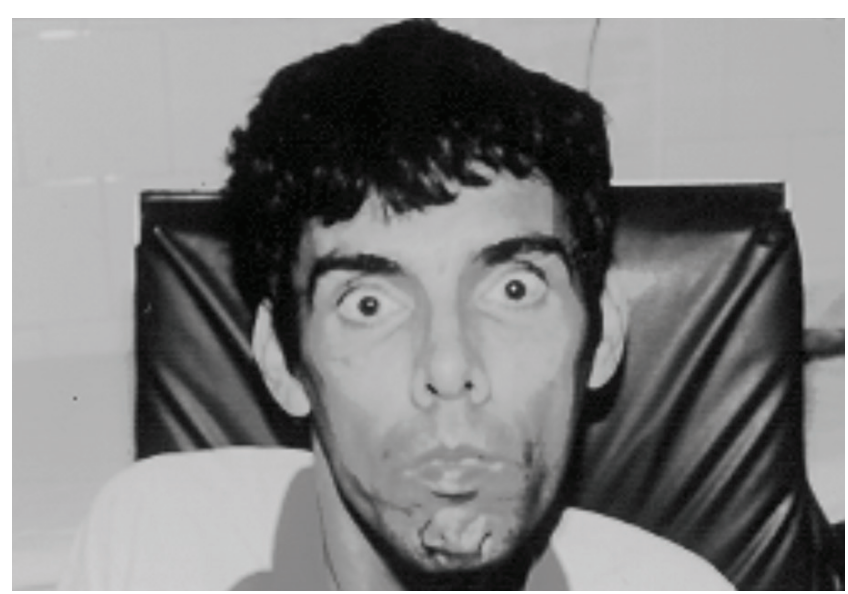

Figure. Patient with spinocerebellar ataxia 3 and bulging eyes. Reproduced with the patient's authorization. with SCA3 than among those with other forms of genetically defined SCA $(\mathrm{p}<0.0001$, Yates correction, OR 37.96 95\%CI 14.6-98.4). There was no correlation between the presence of $\mathrm{BE}$ and the repeat length in the different genes. In the group of 96 SCAs patients without detected mutation BE was found in 9 patients $(9.37 \%)$.

\section{DISCUSSION}

SCA3 is characterized by a high degree of pleomorphism, not only in the variability in the age of onset and in neurological signs but also in the resulting loss of functionality. In general, the initial symptoms occur during adulthood, with a mean age of onset of $32 \pm 12$ years among Brazilian patients ${ }^{3}$. However, the range of age of onset is wide in other series, spanning from 5 to 73 years in Portuguese patients ${ }^{7}$.

Since the classic description of SCA3 by Coutinho and Andrade $^{9}$ in 1978, followed by other studies from the same group, most investigators have emphasized the presence of a characteristic phenotype that includes ophthalmoplegia, BE, facial fasciculations, pyramidal signs, peripheral neuropathy, as well as dystonia in younger patients ${ }^{4,7-9}$. More recently, the observation of variant phenotypes in SCA3 led to the description of sub-phenotypes: subtype I, with predominant extrapyramidal signs and dystonia); subtype II with cerebellar ataxia (CA) and pyramidal tract signs; subtype III (with CA and signs of peripheral neuropathy); subtype IV with parkinsonism; and subtype $\mathrm{V}$ resembling spastic paraplegia9. BE due to eyelids retraction, dystonia, and fasciolingual fasciculations are minor but rather characteristic features of SCA3. In the classical study of Lima e Coutinho ${ }^{4}$ from Portugal, BE was found in $34.8 \%$ of the patients and was considered a very suggestive sign of SCA $3{ }^{4}$.

$\mathrm{BE}$ due to retraction of the eyelids, with consequent widening of the palpebral fissures, was described by James Collier ${ }^{5}$ in 1937, as "tucked lids", and is worldwide known as Collier's sign. In this seminal paper, Collier defined that retraction of the eyelids occurs due to a lesions of the upper brainstem (midbrain), in the region of the posterior comissure, associated with ophtalmoplegia, and frequently found in degenerative diseases ${ }^{5}$.

In this study, BE was present in $33.3 \%$ of patients, however, it was particularly more common among SCA3 patients, occurring in almost two thirds of cases. On the other hand, this ocular finding was detected in only $13.2 \%$ of cases with other SCA (4.7\% of others genetically confirmed SCA and $9.3 \%$ of SCA without genetic diagnosis). Intriguingly, the study by Schöls et al. ${ }^{10}$ describing German patients, did not find the typical signs described in Portuguese SCA 3 cases such as BE, dystonia, and rigidity. These findings were observed in only one out of 42 German patients ${ }^{10}$. This observation is in line with the viewpoint shared by Jacobi et al. ${ }^{11}$ 
Table 1. Demographics of spinocerebellar ataxias patients.

\begin{tabular}{|c|c|c|c|c|c|c|}
\hline Clinical Data & SCA1 & SCA2 & SCA3 & SCA6 & SCA7 & SCA10 \\
\hline Patients number & 9 & 20 & 167 & 3 & 6 & 68 \\
\hline \multicolumn{7}{|l|}{ Gender } \\
\hline Male & 6 & 13 & 92 & 1 & 3 & 32 \\
\hline Female & 3 & 7 & 75 & 2 & 3 & 36 \\
\hline Age of onset (years/mean) & 37.2 & 28.5 & 35.6 & 42.7 & 31.0 & 34.0 \\
\hline Disease duration (years/mean) & 5.89 & 9.20 & 9.02 & 12.67 & 10.67 & 10.68 \\
\hline
\end{tabular}

SCA: spinocerebellar ataxia.

Table 2. Spinocerebellar ataxias: frequency of bulging eyes.

\begin{tabular}{lccc} 
SCA type & Total patients with SCA & Number of patients with BE & $\%$ of BE \\
SCA3 & 167 & 109 & 65.2 \\
Others SC $(1,2,6,7,10)$ & 106 & 5 & 4.7 \\
SCA (without mutation) & 96 & 9 & 9.4 \\
\hline
\end{tabular}

SCA: spinocerebellar ataxia; BE: bulging eyes.

among other groups, who state that there is a significant overlapping among different SCA, impeding purely clinical based diagnoses ${ }^{11}$.

Stevanin, Dürr and Brice ${ }^{12}$ suggested that BE is not common among non-Portuguese Western European SCA3 patients, and might, therefore, be related to ethnic background. Finally, other authors have attempted to describe oculomotor phenotypes suggestive of several forms of $\mathrm{SCA}^{13}$; however these finding have no significant impact in daily clinical practice.

The phenotypic difference among Brazilian and Portuguese patients with SCA3 and patients from others countries (particularly European countries, such as, Germany and France), regarding the presence of $\mathrm{BE}$, could be explained by many reasons, including the role of others regulatory genes, as well as environment factors. However, if one compare the frequency of BE in Portuguese SCA3 patients (33.4\%) with Brazilian SCA3 patients in the present series $(65.2 \%)$, it is noticeable that the frequency of BE in our series is very significant.

In this large Brazilian cohort of SCA patients BE was detected in the majority of patients with SCA3 (65.2\%) and could be used as a clinical tool for the differential diagnosis of SCA.

\section{References}

1. van de Warrenburg BP, Sinke RJ, Verschuuren-Bemelmans CC, et al. Spinocerebellar ataxias in the Netherlands: prevalence and age at onset variance analysis. Neurology 2002;58:702-708.

2. Teive HAG, Munhoz RP, Arruda WO, et al. Spinocerebellar ataxiasGenotype-Phenotype correlation in 104 Brazilian families. Clinics 2012;67:443-449.

3. Jardim LB, Silveira I, Pereira ML, et al. A survey of spinocerebellar ataxia in South Brazil - 66 new cases with Machado-Joseph disease, SCA7, SCA8, or unidentified disease-causing mutations.J Neurol 2001;248:870-876.

4. Lima L, Coutinho P. Clinical criteria for diagnosis of Machado-Joseph disease: report of a non-Azorean Portuguese family. Neurology 1980;30:319-322.

5. Collier J. Nuclear ophtalmoplegia, with especial reference to retraction of lids and ptosis and to lesions of posterior commissure. Brain 1927;50:488-498.

6. Miller NR, Newman NJ (ed). Walsh \& Hoyt's Clinical Neuro-Ophthalmology. $1^{\text {st }}$ vol. $3^{\text {rd }}$ ed. Philadelphia: Lippincott Williams \& Wilkins; 1969.

7. Sequeiros J, Coutinho P. Epidemiology and clinical aspects of Machado-Joseph disease. Adv Neurol. 1993;61:139-153.
8. Coutinho P. Doença de Machado-Joseph. Tentativa de definição. Tese de Doutorado, Porto, Portugal, 1992.

9. Coutinho P, Andrade C. Autosomal dominant system degeneration in Portuguese families of the Azorean islands: a new genetic disorder involving cerebellar, pyramidal, extrapyramidal and spinal cord motor functions. Neurology 1978;28:703-709.

10. Schöls L, Amoiridis G, Epplen JT, Langkafel M, Przuntek H, Riess O. Relations between genotype and phenotype in German patients with the Machado-Joseph disease mutation. J Neurol Neurosurg Psychiatry 1996;61:466-470.

11. Jacobi H, Hauser TK, Giunti P, et al. Spinocerebellar ataxia types 1, 2, 3 and 6 : the clinical spectrum of ataxia and morphometric brainstem and cerebellar findings. Cerebellum 2012;11:155-156.

12. Stevanin G, Dürr A, Brice A. Clinical and molecular advances in autosomal dominant ataxias: from genotype to phenotype and physiopathology. European J Hum Genet 2000;8:4-18.

13. Buttner N, Geschwind D, Jen JC, Perlman S, Pulst SM, Baloh RW. Oculomotor phenotypes in autosomal dominant ataxias. Arch Neurol 1998;55:1353-1357. 